\title{
THE INVESTIGATION OF USING ZIRCONIUM OXIDE MICROSPHERES IN PAPER COATING
}

\author{
Yasemin Sesli (D), Zafer Ozomay (D), Emine Arman Kandirmaz (D), Arif Ozcan \\ Marmara University, School of Applied Sciences, Printing Technologies, Istanbul, Turkey
}

\begin{abstract}
Paper and cardboard are the raw materials frequently used in the printing industry. Pulp structure in papermaking process, surface roughness, and strength of electricity, moisture, thickness, thermal conductivity and optical properties are important parameter that influences printing quality. The surface structure of paper and cardboard needs to be improved for the quality prints. Among the methods of reducing paper surface roughness, sizing, coating and calendering processes can be counted. In the surface coating process, fillers are added to the formulations differently from sizing. While these fillers increase absorption, they also affect colour, opacity, gloss, surface roughness, contact angle etc. Materials containing zirconium oxide; due to the increase of strength, unaffected by chemical agents, high opacity and whiteness, it finds different usage area. In this study sizing and surface coating processes have been carried out in order to improve the surface properties of the paper, to improve the gloss, yellowness, whiteness, absorbency and contact angle of the paper. For this purpose, cationic starch and zirconium oxide coating formulations were prepared and applied onto paper with a paper coating tester under laboratory conditions. In addition, surface sizing with cationic starch has been done as a reference. Coated, sized and standard office type base papers were printed with IGT C1 offset printing test with magenta ink. The colour and gloss values of all printed and unprinted samples were measured. Printed samples, coated papers, surface sized papers and base papers were subjected to lightfastness test according to BS4321 and colour and gloss changes were examined with blue wool scale. The contact angle, absorbency and surface energies of all the obtained surfaces were determined. As a result, it has been found that zirconium oxide-added paper coatings have less glossy but lower contact angle and higher absorbency than surface sizing. It has been determined that the coated paper have worst yellowness and gloss changes with light aging. As a result, the addition of zirconium oxide to the coating improves printability.
\end{abstract}

Key words: zirconium oxide, surface coating, surface energy, contact angle, sizing

\section{INTRODUCTION}

Paper is a composite structure with different porosity ratios of cellulose fibers (Thompson, 2004). But nowadays, paper is not used in industry as raw. Expectations also increased due to the development of visual media and the increase in consumer expectations. Printability parameters (smoothness, roughness, brightness, opacity and whiteness) of the paper must be good for the printing industry (Özcan et al, 2017). In print systems, print quality is strongly dependent on the adherence of paper and ink, and the fixation of the ink on the printing material. The surface characteristics of the paper are of great importance in the process of absorption and settling of the liquid ink to the paper surface. The surface properties of the paper directly affect the print quality. Surface smoothness or roughness is the most important feature of paper (Aydemir, 2014). The coating is one of the processes to give some properties on paper. The main purpose of this process is to fill the gaps on the paper by covering a thin film of pigment, binder and various additives on the base paper to coat a smooth surface. Pigment is one of the components of the coating process, and one or more pigments used in the coating in an amount ranging (Lehtinen, 2000).

Zirconium oxide is used in for aesthetic purposes in dentistry with its surface shape, transparency and colour feature; as a building material for nuclear reactors due to their high melting point, corrosion resistance and low neutron absorption; due to the flammable property in the military; making magnet due to its super conductive property at low temperatures (Çalışır, 2011; Tosun, 2007). In this study, surface sizing and surface coating processes were performed with the aim of developing the surface properties of paper with zirconium oxide (improvement of gloss, jaundice, absorbency and contact angle of paper).

The contact angle is measured by forming a liquid drop on a solid standing on a flat and horizontal plane. Surface tension exists on all interfaces; It is called inter-surface tension or "inter-surface free energy" (Erbil, 1997). The contact angle was first proposed and formulated by Young (Young, 1805) as the angle between the solid surface and the tangent drawn to the droplet surface passing through the triple point of the airliquid-solid phases (Farris et al, 2011). In terms of printability, low contact angle on paper surface is 
desirable. Offset printing is important for water-ink balance, which means that if the contact angle is low, it means wetting more areas with less humidity, which means more bright colours and fewer problems. In case of surface coating, low contact angle causes more area to get wet. Thanks to the -OH groups in the structure of binders such as starch, they form more hydrogen bonds with water and allow for printing with less ink to larger areas.

\section{METHODS}

In order to determine the effect of zirconium oxide microparticles on the printability, $\mathrm{Zr}$ powder was obtained from Alfa Aesar. Particle size distributions of all powder were determined on Malvern Mastersizer equipment. The powder characteristics of $\mathrm{ZrO}_{2}$ used in this study are given in Table 1.

Table 1: Powder characteristics $\mathrm{ZrO}_{2}$ powder.

\begin{tabular}{ll} 
Item & Zr \\
\hline Vendor & Alfa Aesar \\
Shape & Irregular \\
Theoretical density, $\mathbf{g} / \mathbf{c m}^{3}$ & 6.51 \\
Particle size & \\
$\qquad$ D $_{\mathbf{1 0}}$ & 1.95 \\
D $_{\mathbf{5 0}}$ & 6.97 \\
D $_{\mathbf{9 0}}$ & 26.72 \\
Purity, \% & 99.9
\end{tabular}

Uncoated papers with $80 \mathrm{~g} / \mathrm{m}^{2}$ grammage were used in surface sizing and coating operations. The parameters of base paper used in this study are given in Table 2. Cationic starch-based surface sizing was applied on the standard paper surfaces to the control group. Mixture of cationic starch with $7.5 \%$ concentration was heated to $90^{\circ} \mathrm{C}$ for this process. This hot sizing solution was cooled down to $60^{\circ} \mathrm{C}$ afterwards, and it was applied on the surface of paper with Meyer rod (Number 2) in the paper coating device. Then, the same process was repeated for the coating operations, too, and $2.7 \% \mathrm{ZrO}_{2}$ was added to the sizing solution in addition. The surface sizing was applied for drying, and coated paper samples were both left in air-drying for 24 hours at $23 \pm 1^{\circ} \mathrm{C}$ and $50 \pm 2 \%$ relative humidity.

Table 2: Parameters of the base paper used in the study

\begin{tabular}{lll} 
Properties & Standard & Paper \\
\hline Grammage $\left(\mathrm{g} / \mathrm{m}^{2}\right)$ & ISO 536 & 80 \\
Thickness $(\mu \mathrm{m})$ & TAPPI T411 & 190 \\
Whiteness $(\mathrm{D} 65 / 10)(\%)$ & ASTM E313 & 99 \\
Gloss (TAPPI 60 $\left./ 75^{\circ}\right)$ & T480 om-92 & 4.9 \\
Yellowness & ASTM E313 & 0.06 \\
\hline
\end{tabular}

The original, sized and coated papers were printed with Dyoboard DB-5600 Process Magenta commercial offset printing ink using an IGT C1 offset printability test device under $300 \mathrm{~N} / \mathrm{m}^{2}$ pressure printing conditions. CIE L*a*b* values of the print results were measured using X-Rite eXact hand-held spectrophotometer according to ISO 12647-2:2013, between a spectral range of $400 \mathrm{~nm}$ to $700 \mathrm{~nm}$, under a D50 light source, $2^{\circ}$ observer, polarized filter, and 0/45-degree geometry. The colour differences formula was given below. Calculations were made by taking the average of five measurements. $\Delta \mathrm{L}^{*}, \Delta \mathrm{a}^{*}, \Delta \mathrm{b}^{*}$ : Difference in $L^{*}, a^{*}$, and $b^{*}$ values between specimen colour and target colour. 
Lightness is represented by the $L^{*}$ axis which ranges from White to Black. The red area is connected to the green by the $a^{*}$ axis, while the $b^{*}$ axis runs from yellow to blue.

$\Delta E=\sqrt{\Delta L^{2}+\Delta a^{2}+\Delta b^{2}}$

Gloss measurements were made with BYK-Gardner GmbH glossmeter according to ISO 2813:2014 60 geometry. All printed and unprinted samples were subjected to light aging test in accordance with BS 4321:1969 standard. Following the light aging test, CIE L*a*b*, gloss and yellowness measurements were performed one more time for all the samples. For light aging procedure, first of all the CIE L*a*b* colour values and gloss of the samples were measured. Then, printed and non-printed samples were exposed to light aging in a sealed cabinet on the Solarbox 1500 device under constant UV light for 192 hours according to BS 4321-1969 standard. The CIE L*a*b* colour and gloss values of the printed and unprinted samples exposed to fading were measured one more time, and the differences between the initial values and values measured after the light-fastness test were calculated. The contact angle and total surface energy measurements of the papers were performed by PocketGoniometer PGX+ in accordance with ASTM D5946 standard.

\section{RESULTS AND DISCUSSION}

SEM image and size distribution of zirconium oxide microparticles are given in Figure 1. Zirconium particle size is polydisperse and the largest particle has been determined to be $10 \mu \mathrm{m}$. This creates the desired porous surface for the coating process.

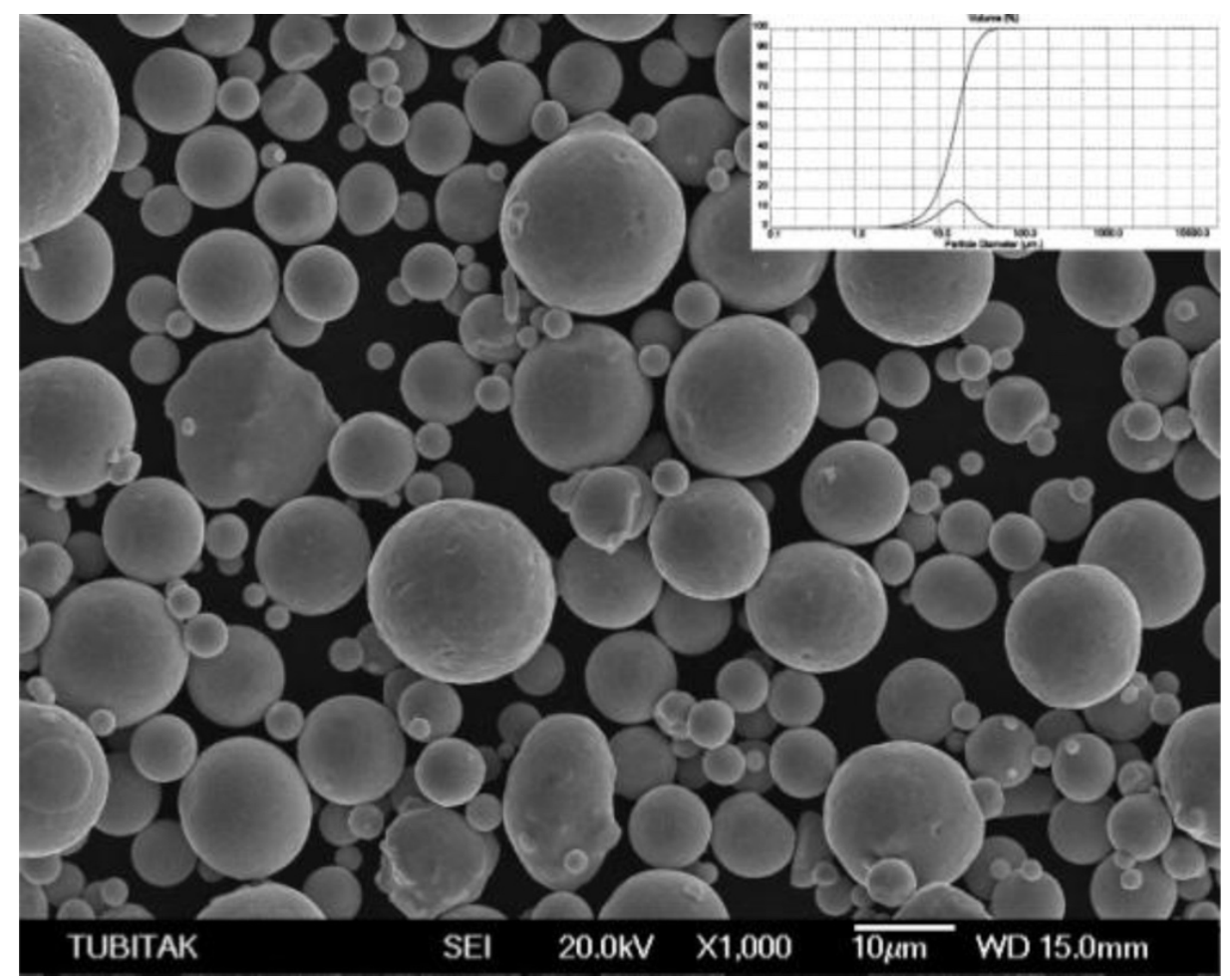

Figure 1: Scanning electron micrograph of $\mathrm{ZrO}_{2}$ powder and particle size distribution curve

The colour properties were measured after complete drying on coated, sized and uncoated paper. Colour is calculated by delta $\mathrm{E}$ of transactions uncoated how it differs from paper. When Figure 2 is examined, it is concluded that the sizing process does not change the colour much and delta difference is not detected by the eye because it is below 3. However, it was determined that the colour changed very much in the coating process and shifted towards yellow. The reason for this shift is added into the origin zirconium coating. The colour of zirconium is yellowish white and the microparticulation increases the roughness and the light is more yellow. 


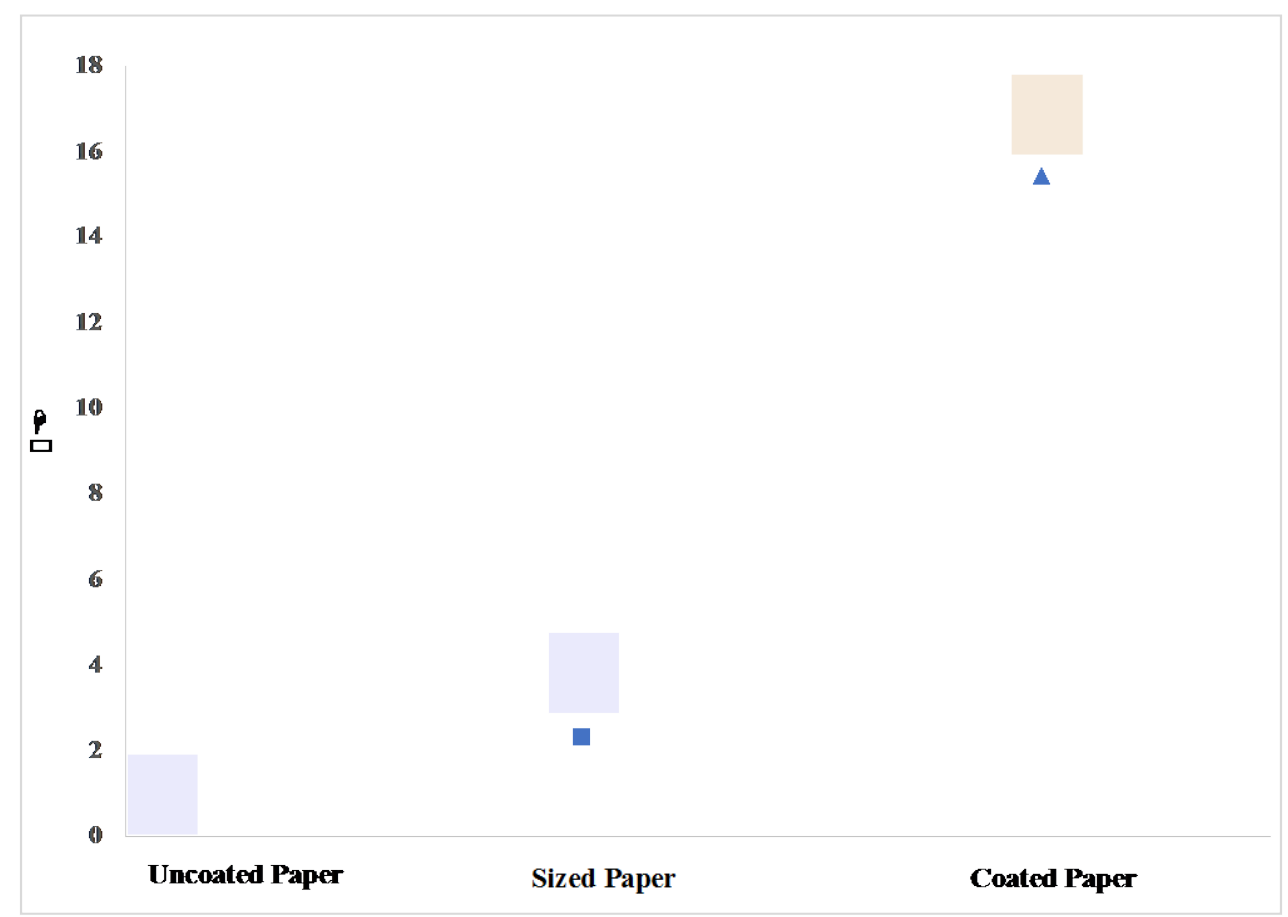

Figure 2: Colour differences of coated, sized and uncoated paper

The gloss of coated, sized and uncoated paper was measured. When the obtained data were examined (Figure 3), it was determined that the most glossy paper belonged to the sized paper containing the most binders. It has been seen that the processes are made more glossier than uncoated paper. Because more polymers were added to the environment, this caused an increase in the crystalline gloss of the polymer. Zirconium, which is added to the coating, creates folds on the surface and has a gloss smaller than the size paper because it causes the diffusion of light.

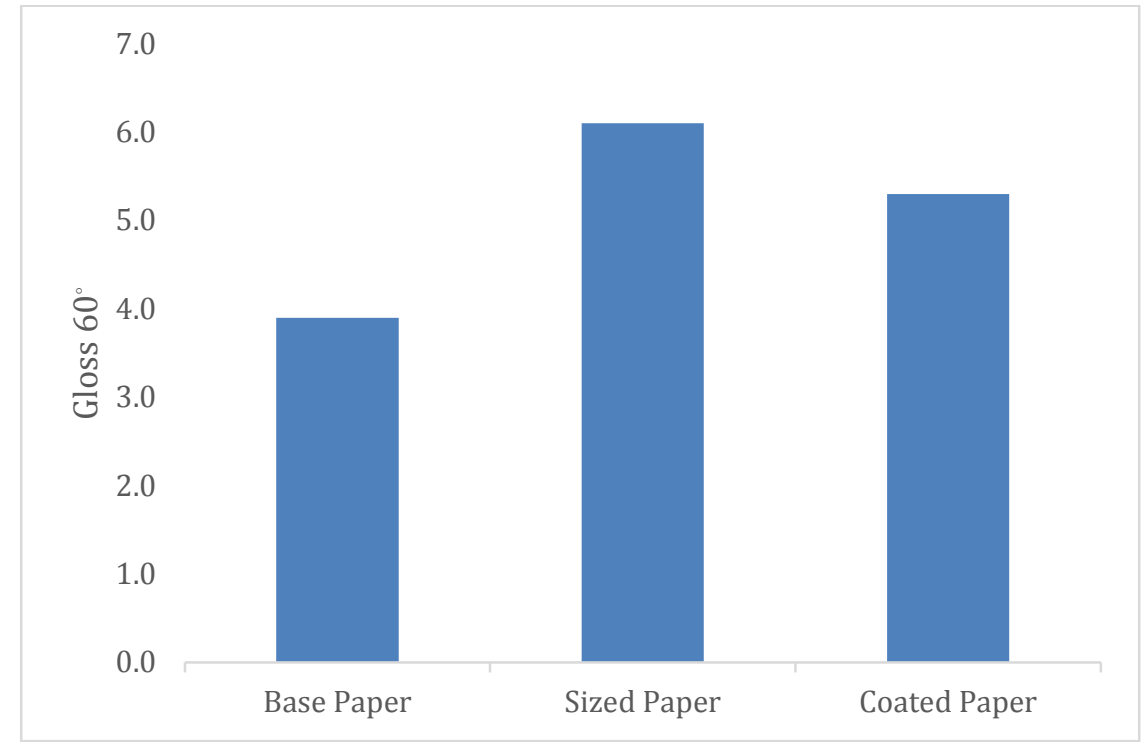

Figure 3: Gloss changes of coated, sized and uncoated paper

Total surface energy (Table 3) results showed that base paper has the lowest surface energy, zirconium coated paper has highest surface energy. The roughness of the zirconium microparticles on the surface reduces the contact angle, thus providing better wettability, i.e., less space to be printed. Surface energy and contact angle values were compatible with each other. 
Table 3: Total surface energy and Contact Angle values according to ASTM D5946 method

\begin{tabular}{lcc} 
Process & $\begin{array}{c}\text { Total Surface Energy } \\
\left(\mathbf{m} \mathbf{J} / \mathbf{m}^{\mathbf{2}}\right)\end{array}$ & $\begin{array}{c}\text { Contact } \\
\text { Angle }\end{array}$ \\
\hline Base paper & 33,8 & 86,5 \\
Coated paper & 52,9 & 33,5 \\
Sized paper & 50,3 & 36,4 \\
\hline
\end{tabular}

The prints were made on three different paper and colour properties were compared. When Figure 4 is examined, there is a noticeable differentiation in the colour of the printing on the treated paper. Because the paper and the pigments were not allowed to be dragged into the paper, thus the colour became more exacerbated and increased to some yellow. This means printing in more areas with less ink in print. So, the printing has been improved. Also, zirconium gave a little more absorbency and increased the colour difference.

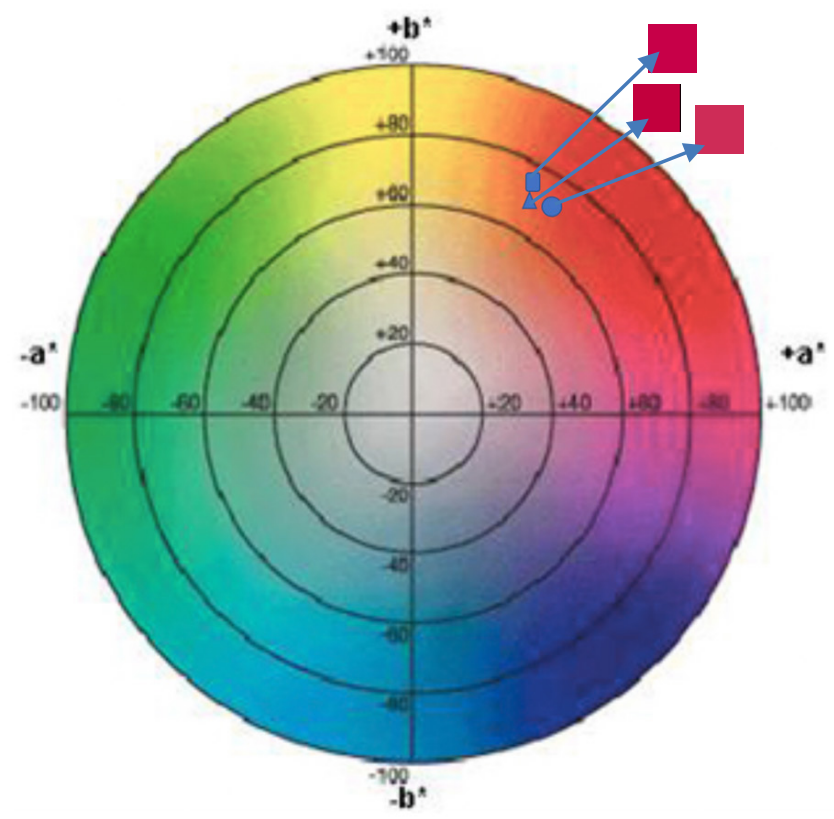

Figure 4: Colour changes of coated, sized and uncoated printed paper

The glosses of printed papers are similar to unprinted papers; however, it has been found that the gloss values are greatly increased due to the resin in the ink content (Figure 5).

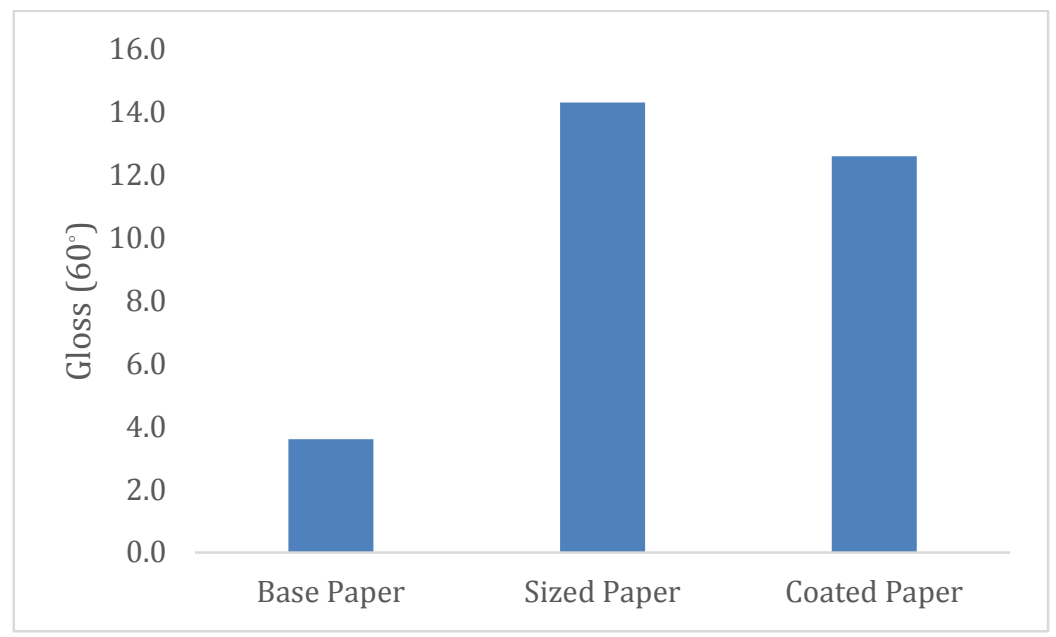

Figure 5: Gloss changes of coated, sized and uncoated printed paper 


\section{CONCLUSIONS}

As a result, zirconium microparticles were produced and used in paper coating. Zirconium added coated papers printed with less ink. The gloss of both coatings and printed paper is enhanced by the processing. However, the shifting of the colour to yellow is a negative feature in the coating. Some negative influencing component (blue pigment) into ink can be eliminated from this problem. For this reason, it is determined that zirconium oxide can be used effectively in paper coatings.

\section{ACKNOWLEDGMENTS}

This work was supported by Marmara University, Scientific Research Projects Committee (M.U. BAPKO) under grant FEN-D- 060918-0513.

\section{REFERENCES}

[1] Aydemir, C.: “Kağıdın Yüzey Pürüzlülüğünün, Baskı Renk Değişimi, Işık Haslığı ve Baskı Parlaklığına Etkisi", Marmara Fen Bilimleri Dergisi, 26 (3), 81-88, 2014.

[2] Birdi, K.S.: "Handbook of Surface and Colloid Chemistry", (Boca Raton, CRC Press Inc., 1997), pages 259-306.

[3] Çalışır, G.H.: "Farklı Zirkonyum Oksit Altyapılar Üzerine Farklı Teknikler ile Uygulanan Üstyapı Porseleninin Renk ve Şeffaflık Üzerine Etkilerinin İncelenmesi", PhD Thesis, İstanbul Üniversitesi Sağlık Bilimleri Enstitüsü, Protetik Diş Tedavisi ABD, 2011.

[4] Farris, S., Introzzi, L., Biagioni, P., Holz, T., Schiraldi, A., Piergiovanni, L.: „Wetting of biopolymer coatings: Contact angle kinetics and image analysis investigation“, Langmuir, 27 (12), 7563-7574, 2011. doi: 10.1021/la2017006

[5] Lehtinen, E.: "Pigment Coating and Surface Sizing of Paper", (Fapet Oy, Helsinki, 2000.), pages 61-66.

[6] Ozcan, A., Zelzele, O.B.: "The effect of binder type on the physical properties of coated paper", MSU Journal of Science, 5 (1), 399-404, 2017. doi: 10.18586/msufbd.322353

[7] Thompson, B.: "Printing Materials: Science and Technology", (Pira International Ltd., Leatherhead, 2004).

[8] Tosun, T.: "Kuron ve köprü protezlerinde zirkonyum", Dentalife, 22, 18- 26, 2007.

[9] Young, T.: "III. An essay on the cohesion of fluids", Philosophical transactions of the royal society of London, 95, 65-87, 1805. doi: 10.1098/rstl.1805.0005

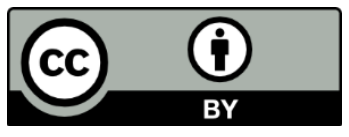

(C) 2018 Authors. Published by the University of Novi Sad, Faculty of Technical Sciences, Department of Graphic Engineering and Design. This article is an open access article distributed under the terms and conditions of the Creative Commons Attribution license 3.0 Serbia (http://creativecommons.org/licenses/by/3.0/rs/). 